\title{
Input respiratory impedance to estimate airway hyperreactivity in children: standard method versus head generator
}

\author{
F. Marchal*, H, Mazurek*, M. Habib*, C. Duvivier**, J. Derelle+, R. Peslin*
}

\begin{abstract}
Input respiratory impedance to estimate airway hyperreactivity in children: standard method versus head generator. F. Marchal, H, Mazurek, M. Habib, C. Duvivier, J. Derelle, R. Peslin. @ERS Journals Ltd 1994.

ABSTRACT: We previously found that a significant underestimation of respiratory mechanical impedance ( $\mathrm{Zrs}$ ) at high frequency may result from the upper airway artefact in children, when pressure is directly varied at the mouth.

To determine the importance of this artefact in estimating lung response to bronchomotor agents with the forced oscillation technique, input respiratory mechanical impedance was measured using 6-32 $\mathrm{Hz}$ pseudorandom pressure oscillations applied directly to the mouth (standard generator (SG)) and around the subject's head (head generator (HG)) in 35 children aged 2.5-13 yrs.

Changes in resistance were generally larger with HG than SG. The mean \pm SEM changes in resistance of the respiratory system (Rrs) at $20 \mathrm{~Hz}$ induced by acetylcholine or allergen challenge were $15 \pm 4 \%$ for SG and $67 \pm 12 \%$ for $\mathrm{HG}$, and changes induced by bronchodilators were $-25 \pm 2 \%$ for SG, and $-46 \pm 4 \%$ for HG $(p<0.01)$. Challenge induced negative frequency dependence of Rrs with SG and positive frequency dependence with HG. There was significant increase in inertance after salbutamol with SG, but no significant change occurred with HG. With both methods, respiratory compliance decreased significantly after challenge. Computer simulations showed that the difference in change in Rrs induced by airway challenge with HG and SG could be explained by the effect of the upper airway wall impedance (Zuaw). Zuaw could also account for the change in inertance and compliance observed with SG, but not for the change in compliance with HG. The latter could be reproduced by simulating unequal distribution of mechanical time constants within the lung, increased peripheral lung resistance with compliant central airways.

It is suggested that the head generator may improve the sensitivity of the forced oscillation technique in evaluating bronchomotor responses in children. The decrease in compliance induced by bronchoconstrictor challenge appears more specific of a physiological response with head generator than with standard generator. Eur Respir J., 1994. 7, 601-607.
\end{abstract}

\begin{abstract}
* Laboratoire d'explorations Fonctionelles Pédiatriques, ${ }^{+}$Service de Médecine Infantile 1, Hôpital d'Enfants, Centre Hospitalier Universitaire de Nancy: **Unité 14 INSERM de Physiopathologie Respiratoire, Vandœuvre lès Nancy, France.
\end{abstract}

\author{
Correspondence: F. Marchal \\ Laboratoire de Physiologie \\ Faculté de Médecine de Nancy \\ BP 184 \\ F-54505 Vandceuvre Lès Nancy \\ France
}

Keywords: Airway reactivity

children

forced oscillation

respiratory mechanical impedance

Received: December 81992

Accepted after revision November 91993

This work was supported by grants from Conseil Général de Meurthe et Moselle. Conseil Régional de Lorraine and INSERM RES 9012.
In young children, the forced oscillation technique may have useful applications in assessing lung function and airway reactivity, because the method is noninvasive, does not require active co-operation, and may provide information on elastic, inertial and flow resistive properties of the respiratory system [I]. Although numerous studies have provided reference values for the input ventilatory impedance in young children (e.g., [2-5]), the effect of upper airway shunting, which may be responsible for a significant error over the frequency range of these measurements, has not been taken into account. This error is particularly marked in patients with airway obstruction $[6,7]$, children $[7,8]$, and infants [9, 10]. Young children are known to have high ventilatory impedance, while estimation of their upper airway wall impedance yields values similar to those reported in adults [8]. Most of the upper airway artefact may be eliminated if pressure is forced around the subject's head (head generator (HG)) rather than directly at the mouth (standard generator (SC)), because the pressure difference - hence flow dissipation - across the upper airway wall is minimal [11]. The former technique may then be very useful in young children, where the upper airway artefact is most prominent.

The practical use and advantages of the head generator over the standard generator in assessing airway reactivity has not been evaluated in young asthmatic children. It may be argued that the shunt impedance of the upper airway will remain constant throughout the study, and will have little effect on the change in resistance induced by the bronchomotor agent, so that the conventional method should provide acceptable results for clinical purpose. Indeed, a recent report indicates that the diagnostic value of this method in childhood asthma is comparable to that 
of body plethysmography or forced expiratory flows [12]. Furthermore, young children may not tolerate the head box. On the other hand, the importance of the upper airway artefact depends on the relative magnitude of upper airway wall and ventilatory impedances, and it may be postulated that the magnitude of the bronchomotor response will depend on the degree of airway obstruction. The aim of this study was to compare standard and head generator techniques in the evaluation of lung response to bronchomotor agents.

\section{Material and methods}

\section{Subjects}

Measurements were performed in 35 children, aged 2.513 yrs, presenting with a history of asthma and referred to the laboratory for assessment of airway reactivity. Based on attack rate, asthma was classified as mild in 23 and moderate to severe in 12. All children had been free of respiratory symptoms for three weeks preceding the challenge, and $\beta$-agonists were withheld for at least $12 \mathrm{~h}$ prior to the test. The study was approved by the Regional Committee on Human Subjects Experimentanon.

\section{Equipment and data processing}

The apparatus for measuring ventilatory impedance (Pulmosfor, SEFAM) has been described in detail previously $[8,13]$, and conformed with the recommendations of the European Working Group on mechanical respiratory impedance [14]. Briefly, respiratory input impedance (Zrs) was measured using pseudorandom pressure oscillations from 6-32 Hz, applied with both the standard technique ( $\mathrm{ZrsSG}$ ) and the head generator technique ( $\mathrm{ZrsHG})$. With the former, pressure variations were only applied at the airway opening and the cheeks were supported. With the latter, they were applied to a 351 chamber enclosing the subject's head and the pneumotachograph, and the cheeks were not supported. Airway flow was measured with a Fleisch No. 1 pneumotachograph connected to a differential pressure transducer (Honeywell $\pm 35 \mathrm{cmH}_{2} \mathrm{O}$ ), and the input pressure was measured with an identical transducer, matched to the first within $1 \%$ of amplitude and 2" of phase up to $32 \mathrm{~Hz}$. The common mode rejection ratio of the flow channel was $60 \mathrm{~dB}$ at $32 \mathrm{~Hz}$. The pneumotachograph was calibrated by the integral method, and the pressure channel with a precision fluid-manometer. The accuracy of the apparatus was checked daily with a physical analogue, and the whole calibration procedure was repeated whenever the measurement was found to deviate by more than $5 \%$ from the expected value. The signals were sampled at a frequency of $128 \mathrm{~Hz}$ for periods of $16 \mathrm{~s}$, and a Fourier analysis was performed by seven blocks of $4 \mathrm{~s}$, with $50 \%$ overlapping. The impedance data from at least two measuring periods were averaged. SG and HG measurements were taken in an unbiased brder and the time interval between the two techniques was 2-3 min. The real part of impedance was analysed in terms of resistance (Rrs) at 10,20 and $30 \mathrm{~Hz}$, and the mean resistance (Rrs) was obtained by averaging values obtained at all frequencies. The change of resistance with frequency (slope; S) was also estimated by linear regression over the entire frequency range. Similarly, total respiratory compliance (Crs) and inertance (Irs) were derived from the reactance (Xrs) data, assuming $\mathrm{Xrs}=\mathrm{Irs} \times \omega-1 /(\mathrm{Crs} \times \omega)$, where $\omega$ is angular frequency ( $\omega=2 \pi \times$ frequency). Resonant frequency ( $f n)$ was calculated as the frequency at which $\mathrm{Xrs}=0$.

\section{Airway reactivity}

Control measurements were obtained prior to any challenge. The response to acetylcholine and to a specific allergen, was tested in 18 and 16 children, respectively. One child was tested after exercise. Aerosols were delivered using a Wright nebulizer. Acetylcholine was given at a dose of $1 \mathrm{mg}$, and respiratory impedance measurements were obtained within $10 \mathrm{~min}$ after the inhalation. Aerosols of allergenic extracts of house dust mites and Altemaria (Alyostal, Stallergenes, Pasteur) were given in cumulative doses, starting from 0.5 IR for mites, and from a solution of $2.5 \% \mathrm{w} / \mathrm{v}$ for Altemaria. Respiratory impedance was measured 10 min after the last dose of the test. Salbutamol was given at a dose of $100 \mu \mathrm{g} \cdot \mathrm{kg}^{-1}$ at the end of each challenge test, and the measurements were similarly obtained IO min thereafter.

\section{Data analysis}

The parameters estimated with the standard generator and the head generator are given the suffix SG and HG, respectively. The significance of the changes in impedance parameters after bronchoprovocation compared with control, and after salbutamol compared with postchallenge values was assessed for each method. The percentage changes in resistance at 10 and $20 \mathrm{~Hz}$, and in compliance induced by bronchoprovocation compared to control, and by salbutamol compared to postchallenge were calculated and compared between methods. Comparisons were made using an analysis of variance. Data are expressed as mean \pm SEM, unless otherwise indicated. Differences between means were considered statistically significant at $\mathrm{p}<0.05$.

\section{Results}

\section{Impedance parameters}

An example of respiratory resistance and reactance measured by ZrsSG and ZrsHG, for control, after bronchial challenge and after subsequent treament with salbutamol, is illustrated in figure 1 . The mean values of impedance parameters under these conditions are reported in table 1 . The resistance at $10 \mathrm{~Hz}$ could be measured in all conditions in only 31 subjects. Both methods show 

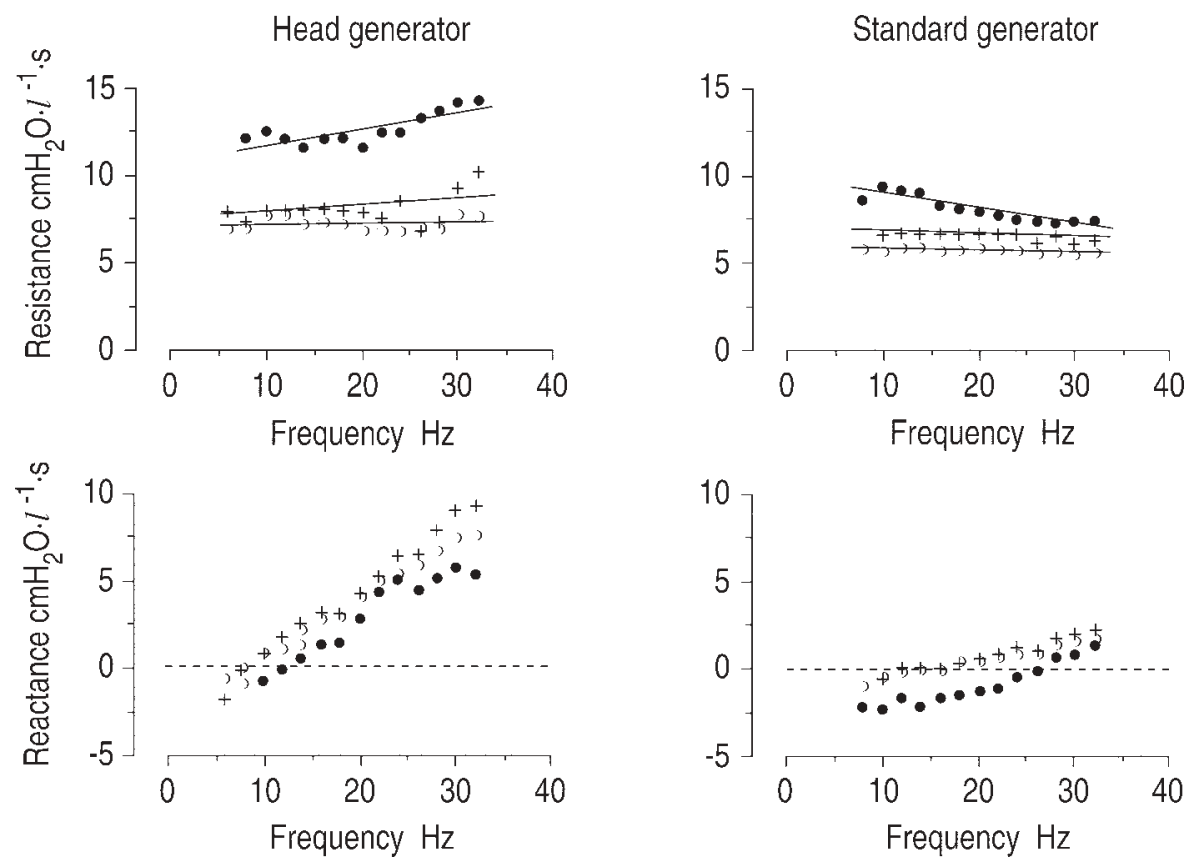

Fig. 1. - Respiratory resistance (upper panels) and reactance (lower panels) vs frequency in a 6 year old with head generator (HG) (left panels) and standard generator (SG) (right panels) at baseline, after bronchial challenge with house dust mite and after subsequent salbutamol treatment. Solid lines are obtained by linear regression analysis. Note that airway challenge (house dust mite, 3 IR) induces a larger increase in resistance and a smaller change in reactance and resonant frequency with HG compared with SG. Also, after challenge, the frequency dependence of resistance is more positive with HG. and more negative with SG. 0 : baseline; $:$ challenge: +; salbutamol.

Table 1. - Impedance parameter before and after bronchial challenge, and after bronchodilation

\begin{tabular}{|c|c|c|c|c|c|c|}
\hline & \multicolumn{3}{|c|}{ Standard generator } & \multicolumn{3}{|c|}{ Head generator } \\
\hline & Control & Provocation & Relaxation & Control & Provocation & Relaxation \\
\hline $\mathrm{Rrs} 10 \dagger \mathrm{cmH}_{2} \mathrm{O} \cdot l^{-1} \cdot \mathrm{s}$ & $8.2 \pm 0.6$ & $9.5 \pm 0.7 *$ & $6.4 \pm 0.4 * *$ & $8.6 \pm 0.6$ & $12.8 \pm 1.2 *$ & $6.7 \pm 0.4 * *$ \\
\hline $\mathrm{Rrs} 20 \mathrm{cmH}{ }_{2} \mathrm{O} \cdot l^{-1} \cdot \mathrm{s}$ & $7.9 \pm 0.5$ & $8.9 \pm 0.5^{*}$ & $6.5 \pm 0.4 * *$ & $8.4 \pm 0.6$ & $14.2 \pm 1.5 *$ & $6.3 \pm 0.4 * *$ \\
\hline $\mathrm{Rrs} 30 \quad \mathrm{cmH}_{2} \mathrm{O} \cdot l^{-1} \cdot \mathrm{s}$ & $7.3 \pm 0.4$ & $8.2 \pm 0.5$ & $6.2 \pm 0.4 * *$ & $9.8 \pm 0.7$ & $16.2 \pm 2.0 *$ & $7.2 \pm 0.5 * *$ \\
\hline Rrs $\quad \mathrm{cmH}_{2} \mathrm{O} \cdot l^{-1} \cdot \mathrm{s}$ & $7.9 \pm 0.5$ & $9.9 \pm 0.5^{*}$ & $6.3 \pm 0.4 * *$ & $9.0 \pm 0.6$ & $14.7 \pm 1.6^{*}$ & $6.7 \pm 0.4 * *$ \\
\hline $\mathrm{s} \times 10^{-2} \mathrm{cmH}_{2} \mathrm{O} \cdot l^{-1} \cdot \mathrm{s}^{2}$ & $-5.9 \pm 1.1$ & $-9.8 \pm 1.7 *$ & $-0.6 \pm 0.8 * *$ & $3.4 \pm 1.5$ & $9.6 \pm 3.5^{*}$ & $0.2 \pm 0.6 * *$ \\
\hline$f \mathrm{n} \mathrm{Hz}$ & $20.2 \pm 1.4$ & $26.2 \pm 3.6^{*}$ & $13.3 \pm 0.9 * *$ & $8.4 \pm 0.3$ & $10.8 \pm 0.9 *$ & $7.2 \pm 0.3 * *$ \\
\hline $\mathrm{h}-\mathrm{S} \times 10^{-2} \mathrm{cmH}_{2} \mathrm{O} \cdot l^{-1} \cdot \mathrm{s}^{2}$ & $1.0 \pm 0.1$ & $1.1 \pm 0.2$ & $1.6 \pm 0.1 * *$ & $4.8 \pm 0.2$ & $4.5 \pm 0.3$ & $4.8 \pm 0.2$ \\
\hline $\mathrm{Crs} \mathrm{ml} \cdot \mathrm{cmH}_{2} \mathrm{O}^{-1}$ & $10.5 \pm 1.0$ & $8.6 \pm 1.2 *$ & $13.3 \pm 0.9 * *$ & $8.5 \pm 0.6$ & $6.8 \pm 0.6^{*}$ & $9.1 \pm 0.6 * *$ \\
\hline
\end{tabular}

Data are presented as mean \pm SEM. $\uparrow: \mathrm{n}=31$; Control: before challenge; Provocation: after bronchial challenge; Relaxation: after bronchodilation with salbutamol after challenge. *: $\mathrm{p}<0.01 v s$ control; **: $\mathrm{p}<0.01$ vs provocation. Rrs 10, Rrs20 and Rrs30: resistance of the respiratory system at 10,20 and $30 \mathrm{~Hz}$, respectively; Rrs: mean resistance of the respiratory system; $\mathrm{S}$ : slope, change of resistance with frequency; fin: resonant frequency; Irs: inertance of the respiratory system: Crs: compliance of the respiratory system.

significant increase in resistance at any frequency after bronchoprovocation compared with control, and a significant decrease after salbutamol compared with the value after bronchial challenge. S measured by the standard generator decreased significantly after bronchoprovocation and increased significantly after salbutamol. An opposite pattern was found with the head generator, namely, a significant increase following provocation and a significant decrease after salbutamol. Resonant frequency by both methods increased significantly after bronchial challenge and decreased significantly after salbutamol. Crs decreased significantly after bronchial challenge and increased after salbutamol by both techniques. Finally, inertance by the standard method was found to increase significantly after salbutamol, but no significant change was found for the head generator.

\section{Change in resistance}

The percentage change in resistance at 10 and $20 \mathrm{~Hz}$ induced by the tests are illustrated in figure $2 \mathrm{a}$ and $\mathrm{b}$. The change measured by the standard generator is clearly smaller compared with the head generator $(p<0.01)$. Interestingly, this difference is larger for bronchoprovocation than for relaxation.

\section{Change in compliance}

The percentage changes in respiratory compliance after provocation and salbutamol are reported in figure $2 \mathrm{c}$. It may be seen that the change observed after provocation is similar for both methods, but the increase in compliance after salbutamol is significantly greater for ZrsSG than ZrsHG. 


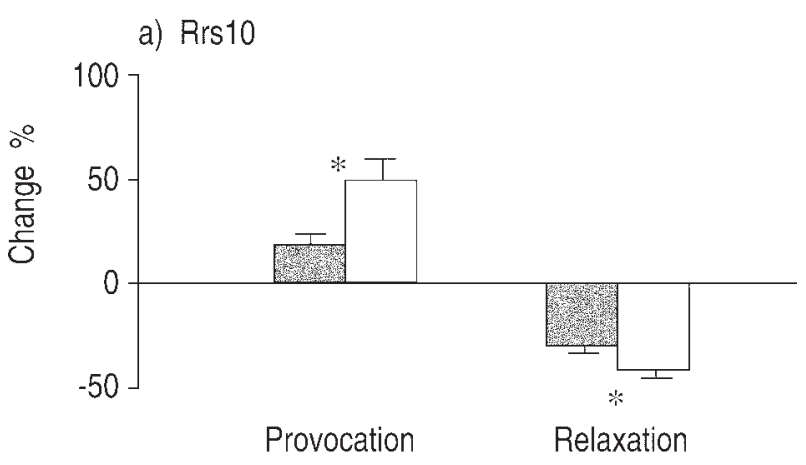

b) Rrs20

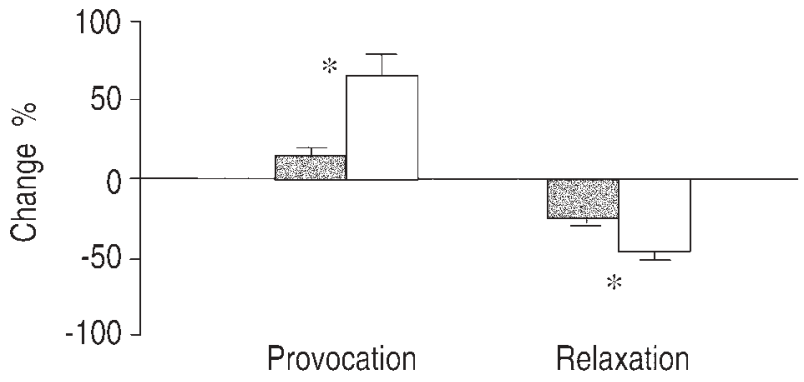

c) $\mathrm{Crs}$

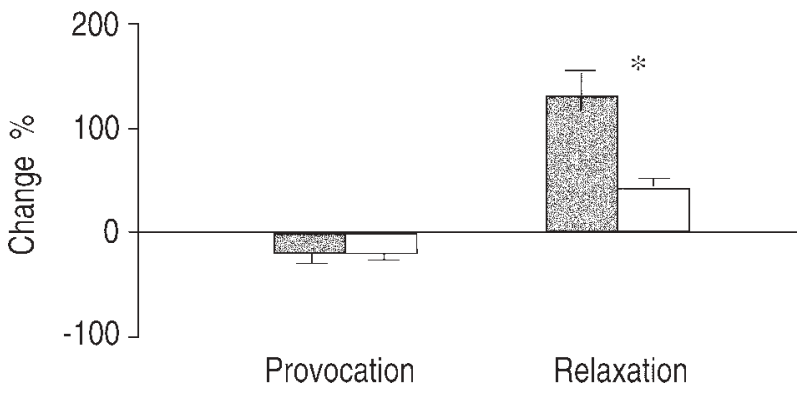

Fig. 2. - Percentage change in resistance at $10 \mathrm{~Hz}$ (a) and $20 \mathrm{~Hz}$ (b) and change in compliance (c) induced by airway provocation from control and by relaxation from postchallenge with standard generator (SG) ( after both challenge and salbutamol is significantly larger for HG than SG. However, the increase in compliance after salbutamol is significantly higher with SG than HG. ${ }^{*}: \mathrm{p}<0.01$. Data are presented as mean \pm SEM (error bars).

\section{Discussion}

Neither method of measuring input respiratory impedance gives an accurate estimation of Zrs. With the standard method, some flow is lost in the upper airway wall motion, according to the impedance of the upper airway wall relative to that of the respiratory system. With the head generator, some flow entering the intrathoracic airways is not measured; the latter error depending on the impedance of the upper airway wall relative to that of the pneumotachograph (fig. 3a). In normal children, it has been found that the error introduced by the head generator was smaller than that resulting from the standard method [8].

The change in resistance induced by challenge and salbutamol are significantly larger for ZrsHG than ZrsSG. However, the difference between the change in RrsSG a)
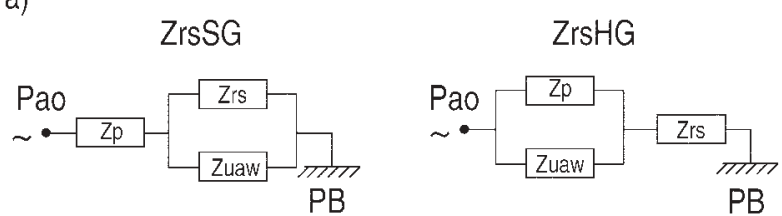

b)
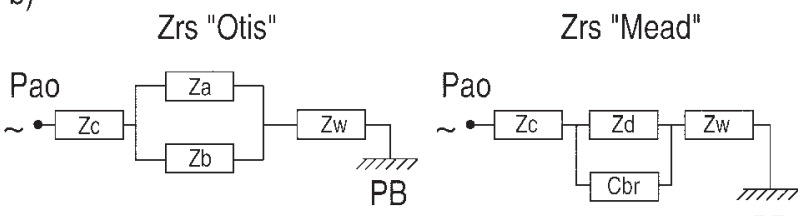

PB

Fig. 3. - Models used to simulate frequency response of respiratory impedance. a) Diagram representing ZrsSG and ZrsHG. With ZrsSG, the respiratory impedance (Zrs) is in parallel with the impedance of the upper airway wall (Zuaw). With ZrsHG, Zuaw is in parallel with the impedance of the pneumotachograph $(\mathrm{Zp})$. Pao: pressure at the airway opening; PB: barometric pressure; SG: standard generator; HG: head generator: b) In the model of OTIS et al. [16] the lung is characterized by two components in parallel $(\mathrm{Za}, \mathrm{Zb})$ that are in series with the chest wall $(\mathrm{Zw})$. The model has also been modified to include a central compartment (Zc). The model of MEAD [IS] consists of the series impedance of central airways $(\mathrm{Zc})$, the impedance of peripheral airways and lung tissue $(\mathrm{Zd}), \mathrm{Zd}$ being shunted by the compliance of central airways (Cbr). The values attributed to each parameter are indicated in Appendix I and 2.

and RrsHG appears to be smaller for the response to salbutamol than for the response to bronchoconstrictors (fig. $2 \mathrm{a}$ and b). Similar results were obtained by computer simulation of effect of upper airway shunting with simple lumped models (Fig. 3a, and appendix 1): RrsHG overestimated the "shunt-free" resistance (Rrs) by a fixed and small amount. In contrast, the underestimation of Rrs by RrsSG increases with Rrs (fig. 4a). In figure 4b, the simulated relationship between RrsSG and RrsHG is compared with that observed in the patients before and after provocation, and after relaxation, as reported in table 1. It may be seen that the patients have control RrsSG and RrsHG that are higher than normal subjects, indicating some degree of airway obstruction. After provocation, RrsHG increases more than RrsSG, roughly 'following mbdel prediction. The change induced by salbutamol is smaller for RrsSG than RrsHG, but is larger than that observed for RrsSG after provocation.

The frequency dependence of resistance becomes more negative after provocation with the standard method and more positive with the head generator, both trends being reversed by salbutamol. Models in figure $3 \mathrm{a}$ include shunt properties of upper airways, and their simulated response 'to airway challenge over the whole frequency interval was calculated as described above. It can be seen that the change in frequency dependence of resistance (fig. 5 and table 2) is similar to that observed in the patients (fig. 1 and table 1). The simulation also shows that Irs $\left(5 \times 10^{-2} \mathrm{cmH}_{2} \mathrm{O} \cdot l^{-1} \cdot \mathrm{s}^{2}\right)$ is underestimated by SG $\left(2.6 \times 10^{-2} \mathrm{cmH}_{2} \mathrm{O} \cdot l^{-1} \cdot \mathrm{s}^{2}\right)$, and overestimated by $\mathrm{HG}$, $\left(5.9 \times 10^{-2} \mathrm{cmH}_{2} \mathrm{O} \cdot l^{-1} \cdot \mathrm{s}^{2}\right)$, although the latter is much less than the former.

These patterns are accentuated after challenge, i.e. IrsSG $=11.9 \times 10^{-2} \mathrm{cmH}_{2} \mathrm{O} \cdot l^{-1} \cdot \mathrm{s}^{2}$, and IrsHG $=6.2 \times 10^{-2}$ $\mathrm{cmH}_{2} \mathrm{O} \cdot l^{-1} \cdot \mathrm{s}^{2}$. These results are in keeping with the clinical 
a)

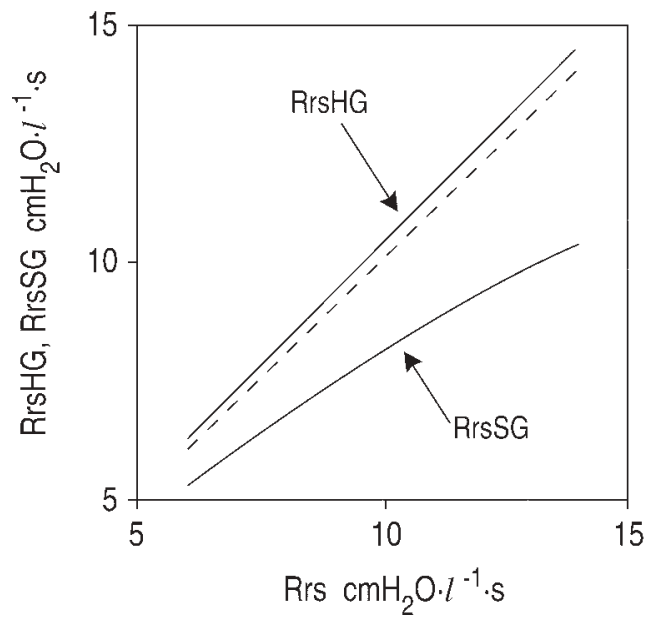

b)

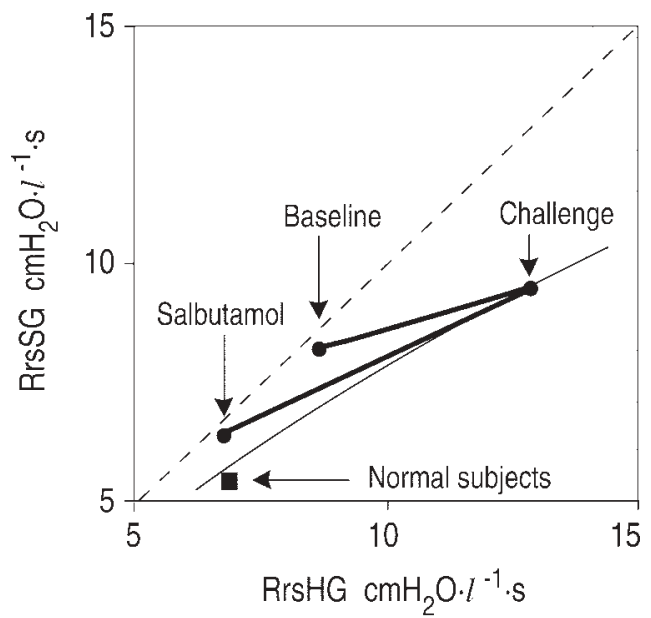

Fig. 4. - a) Relationship between changes in respiratory resistance measured with the standard generator ( $\mathrm{RrsSG})$ and head generator (RrsHG) at $10 \mathrm{~Hz}$ and the "shunt free" resistance (Rrs). Dashed line is line of identity. Note that the overestimation of Rrs by RrsHG is small in comparison with its underestimation by RrsSG. Values of the coefficients for respiratory impedance (Zrs) and upper airways impedance (Zuaw) as in Appendix 1. b) Relationships between RrsSG and RrsHG for the same simulation (thin continuous line), and for the average measurements obtained in baseline conditions, after challenge, and after salbutamol. The square represents the average value previously reported in normal children [8]. Note that the relationship between actual values of RrsSG and RrsHG roughly follows model prediction (curve) i.e. the underestimation of RrsSG is increased with airway obstruction.
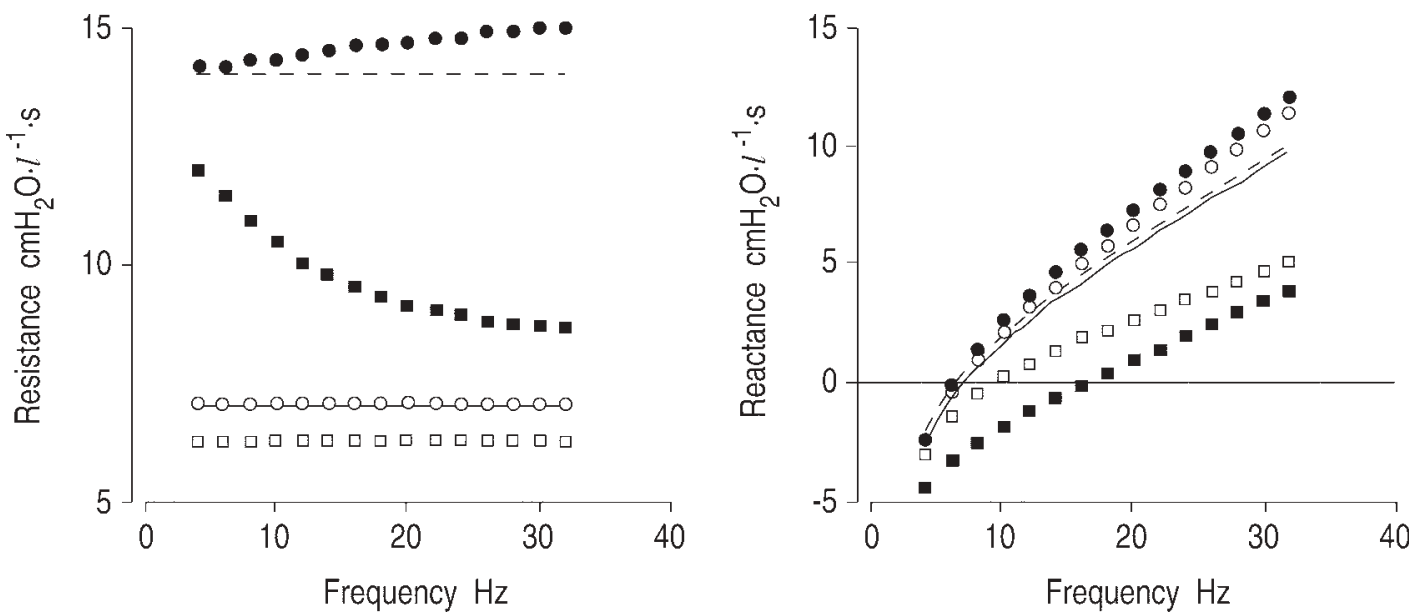

Fig. 5. - Simulation of frequency response of resistance and reactance of Zrs (lines), ZrsSG (squares) and ZrsHG (circles), as defined by the models of figure $3 \mathrm{a}$, when the shunt free resistance increases from 7 (continuous line and open symbols) to $14 \mathrm{cmH} \mathrm{H}_{2} \mathrm{O} \cdot l^{-1} \cdot \mathrm{s}(\mathrm{dotted}$ line and closed symbols). Underestimation and negative frequency dependence of resistance by SG are markedly increased by bronchoconstriction. In contrast, overestimation and positive frequency dependence of resistance by the HG are slightly accentuated by bronchoconstriction. The reactance of Zrs is constant before and after bronchoconstriction. The reactance of ZrsSG is further shifted to the right during bronchcconstriction while the reactance of ZrsHG is slightly shifted to the left. For abbreviations see legend to figure 4.

findings of a significant increase in IrsSG after salbutamol, and a lack of variation in IrsHG (table 1). Actually, Irs is not expected to change, since it depends mainly on central airway dimensions, which are unlikely to be affected by bronchomotor agent.

Finally, this computer simulation shows that airway challenge leads to a marked decrease in CrsSG and a slight increase in CrsHG (table 2), in contrast with patient data, where Crs was found to decrease significantly with both SG and HG (table 1). The measured change in CrsHG may, therefore, not be explained by the upper airway wall motion, and is likely to reflect true physiological alteration associated with airway challenge. For instance, a positive response to challenge could consist of an increase in peripheral airway resistance with compliant central airways (model of MEAD [15]) or uneven distribution of mechanical time constants within the lung (model of OTIS [16]). Simulation of these models (fig. 3b and Appendix 2) are given in table 2. With both, respiratory compliance decreases with challenge (table 2). If the upper airway wall impedance is included by combining models described in figure $3 \mathrm{a}$ and b, CrsSG decreases more than CrsHG after challenge (table 2), in keeping with the larger change in compliance after salbutamol with the standard generator than with the head generator in the patients (fig. 2). It is also of interest that the model of OTIS et al. [16] slightly increases the positive value of SHG, and the negative value of SSG 
Table 2. - Simulation of respiratory compliance (Crs) and slope (S) of the resistance-frequency function before $\left(\mathrm{Rrs}=7 \mathrm{cmH}_{2} \mathrm{O} \cdot H^{-1} \cdot \mathrm{s}\right)$ and after bronchoconstriction $\left(\mathrm{Rrs}=14 \mathrm{cmH}_{2} \mathrm{O} \cdot \digamma^{-1} \cdot \mathrm{s}\right)$

\begin{tabular}{|c|c|c|c|c|c|c|}
\hline \multirow[b]{2}{*}{$\mathrm{Rrs} \mathrm{cmH}_{2} \mathrm{O} \cdot l^{-1} \cdot \mathrm{s}$} & \multicolumn{2}{|c|}{2 nd order } & \multicolumn{2}{|c|}{$\begin{array}{l}\text { Model } \\
\text { OTIS et al. [16] }\end{array}$} & \multicolumn{2}{|c|}{ MEAD [15] } \\
\hline & 7 & 14 & 7 & 14 & 7 & 14 \\
\hline Respiratorvcompliance & & & I & & & \\
\hline $\mathrm{Crs} \quad \mathrm{ml} \cdot \mathrm{cmH}_{2} \mathrm{O}^{-1}$ & 10.0 & 10.0 & 10.0 & 8.1 & 9.7 & 5.3 \\
\hline $\mathrm{CrsSG} \quad \mathrm{ml} \cdot \mathrm{cmH}_{2} \mathrm{O}^{-1}$ & 10.7 & 6.6 & 10.6 & 6.8 & 10.1 & 4.9 \\
\hline $\mathrm{CrsHG} \quad \mathrm{ml} \cdot \mathrm{cmH}_{2} \mathrm{O}^{-1}$ & 10.0 & 10.9 & 10.0 & 8.7 & 9.8 & 5.5 \\
\hline \multicolumn{7}{|l|}{ Slope } \\
\hline $\mathrm{S} \quad 10^{-2} \quad \mathrm{cmH}_{2} \mathrm{O} \cdot l^{-1} \cdot \mathrm{s}^{2}$ & 0 & 0 & 0 & -1.0 & -2.7 & -26.1 \\
\hline $\mathrm{S} \mathrm{S} \mathrm{G} 10^{-2} \mathrm{cmH}_{2} \mathrm{O} \cdot l^{-1} \cdot \mathrm{s}^{2}$ & -0.06 & -7.9 & -do6 & -11.3 & -1.9 & -18.4 \\
\hline SHG $10^{-2} \mathrm{cmH}_{2} \mathrm{O} \cdot l^{-1} \cdot \mathrm{s}^{2}$ & 0.02 & 3.2 & 9.02 & 2.8 & -2.7 & -26.3 \\
\hline
\end{tabular}

These coefficients are estimated from data generated by simulating a second order model, and the models of OTIS et al. [16] and MEAD [15], without (first line) and with the 'effect of Zuaw in the standard method (second line) and the head generator (third line). Rrs: resistance of the respiratory systems; SG: standard generator; HG; head generator; Zuaw: impedance of the upper airway.

in response to challenge. In contrast, the model of MEAD [15] is associated with a large increase in negative frequency dependence after challenge for both methods (table 2).

In summary, resistance, frequency dependence of resistance and inertance measured after provocation or relaxation change in a different pattern with SG and HG. These differences may be explained by upper airway wall motion. However, the change in CrsSG may be explained by the combined effect of upper airway wall motion and some form of lung inhomogeneity, while only the latter may account for the change in $\mathrm{CrsHG}$. The head generator may improve the sensitivity of the forced oscillation technique in evaluating airway response to challenge by decreasing the shunt flow in the upper airway wall. However, further studies are required to assess the ability of the head generator to identify response to airway challenge/relaxation, in comparison with other methods (e.g. plethysmography or forced expiration).

Acknowledgements: The authors thank B. Chalon, C. Choné, G. Colin, B. Delorme, F. Fortin and S. Méline for their skilful technical assistance and M. Schaller for the typing.

\section{Appendix 1}

Impedances measured with the standard generator (ZrsSG) and the head generator (ZrsHG), are simulated according to the models described in figure $3 \mathrm{a}$, corresponding to the following equations, as described by PESLIN et al. [11]:

$$
\begin{aligned}
& \mathrm{ZrsSG}=\mathrm{Zrs} \times \mathrm{Zuaw} /(\mathrm{Zrs}+\mathrm{Zuaw}) \\
& \mathrm{ZrsHG}=\mathrm{Zrs}(1+\mathrm{Zp} / \mathrm{Zuaw})
\end{aligned}
$$

where $\mathrm{Zp}$, the impedance of the pneumotachograph, is approximated by a resistance $\left(\mathrm{Rp}=1.1 \mathrm{cmH}_{2} \mathrm{O} \cdot l^{-1} \cdot \mathrm{s}\right)$ and an inertance $\left(\mathrm{Ip}=0.5 \times 10^{-2} \mathrm{cmH}_{2} \mathrm{O} \cdot l^{-1} \cdot \mathrm{s}^{2}\right)$, and $\mathrm{Zrs}$, the "shunt free" respiratory impedance, and Zuaw, the upper airway wall impedance, are approximated by second order systems, i.e. series of resistance (Rrs, Ruaw), inertance (Irs, Iuaw) and compliance (Crs, Cuaw). The general equation of these impedances $(\mathrm{Z})$ is:

$$
\mathrm{Z}=\mathrm{R}+(\mathrm{I} \omega-1 / \mathrm{C} \omega) \mathrm{j}
$$

where $\mathrm{R}, \mathrm{I}$ and $\mathrm{C}$ are, respectively, resistance, inertance and compliance and $\mathrm{j}=\sqrt{ }-1$, is the unit of imaginary numbers!

To simulate a positive airway response to challenge, $\mathrm{Rrs}$ is made to increase from 7 to $14 \mathrm{cmH}_{2} \mathrm{O} \cdot l^{-1} \cdot \mathrm{s}$. Irs and $\mathrm{Crs}$ are kept constant (respectively, $5 \times 10^{-2} \mathrm{cmH}_{2} \mathrm{O} \cdot l^{-1} \cdot \mathrm{s}^{2}$ and $10 \mathrm{ml} \cdot \mathrm{cmH}_{2} \mathrm{O}^{-1}$ ). Indeed, Irs is mainly contributed to by central airways and should not show much change after provocation. The contribution of lung viscoelastic properties to respiratory compliance at the frequencies studied should be small. Ruaw, Iuaw and Cuaw are, respectively, of $10 \mathrm{cmH}_{2} \mathrm{O} \cdot l^{-1} \cdot \mathrm{s}, 3 \times 10^{-2} \mathrm{cmH}_{2} \mathrm{O} \cdot l^{-1} \cdot \mathrm{s}^{2}$ and $1.2 \mathrm{ml} \cdot \mathrm{cmH}_{2} \mathrm{O}^{-1}$. To allow for the effect of holding the cheeks, Zuaw is doubled with the standard method. The reference values of Zrs and Zuaw are taken from a previous study in normal children of similar age [8].

By taking the real and imaginary part of ZrsSG and ZrsHG at each even frequency between 6 and $32 \mathrm{~Hz}$, the resistance and its frequency dependence on the one hand, and inertance and compliance on the other, can be calculated as explained in the Methods section, and compared to the respective coefficients calculated for the ideal "shunt-free" respiratory impedance (Zrs).

\section{Appendix 2}

The effects of unequal distribution of ventilation (model of ОTIS et al. [16]) or airway compliance. (model of MEAD [15]) on the coefficients calculated as for a 
second order system can be simulated similarly. These models are presented in fig. $3 \mathrm{~b}$. The chest wall ( $\mathrm{Zw})$, represented by a resistance $\left(\mathrm{Rw}=2 \mathrm{cmH}_{2} \mathrm{O} \cdot l^{-1} \cdot \mathrm{s}\right)$ and a compliance $\left(\mathrm{CW}=12.5 \mathrm{ml} \cdot \mathrm{cmH}_{2} \mathrm{O}^{-1}\right)$, has been included in both models.

The model of OTIS et al. [16] has also been slightly modified to include a central compartment constituted by a resistance $\left(\mathrm{Rc}=2 \mathrm{cmH}_{2} \mathrm{O} \cdot l^{-1} \cdot \mathrm{s}\right)$ and an inertance $\left(\mathrm{Ic}=5 \times 10^{-2} \mathrm{cmH}_{2} \mathrm{O} \cdot l^{-1} \cdot \mathrm{s}^{2}\right)$. Hence, $\mathrm{Zrs}$ is given by:

$$
\mathrm{Zrs}=\mathrm{Zc}+\mathrm{Za} \times \mathrm{Zb} /(\mathrm{Za}+\mathrm{Zb})+\mathrm{Zw}
$$

The two compartments in parallel $(\mathrm{Za}, \mathrm{Zb})$ are each constituted by a resistance ( $\mathrm{Ra}, \mathrm{Rb})$ and a compliance $(\mathrm{Ca}, \mathrm{Cb})$. Before challenge, $\mathrm{Ra}=\mathrm{Rb}=6 \mathrm{cmH}_{2} \mathrm{O} \cdot l^{-1} \cdot \mathrm{s}$ and $\mathrm{Ca}=\mathrm{Cb}=25 \mathrm{ml} \cdot \mathrm{cmH}_{2} \mathrm{O}^{-1}$. Both time constants are equal: $\mathrm{Ra} \times \mathrm{Ca}=\mathrm{Rb} \times \mathrm{Cb}=0.15 \mathrm{~s}$, and the total respiratory resistance is $7 \mathrm{cmH}_{2} \mathrm{O} \cdot l^{-1} \cdot \mathrm{s}$. After challenge, Rrs increases to $14 \mathrm{cmH}_{2} \mathrm{O} \cdot l^{-1} \cdot \mathrm{s}$, and the inhomogeneity of the lung is simulated by inequalities of time constants, $(\mathrm{Ra} \times \mathrm{Ca}=1.75 \mathrm{~s}$ and $\mathrm{Rb} \times \mathrm{Cb}=0.19 \mathrm{~s}$ ), with $\mathrm{Ra}=50 \mathrm{cmH}_{2} \mathrm{O} \cdot l^{-1} \cdot \mathrm{s}, \mathrm{Rb}=12.5$ $\mathrm{cmH}_{2} \mathrm{O} \cdot l^{-1} \cdot \mathrm{s}, \mathrm{Ca}=35 \mathrm{ml} \cdot \mathrm{cmH}_{2} \mathrm{O}^{-1}$ and $\mathrm{Cb}=15 \mathrm{ml} \cdot \mathrm{cmH}_{2} \mathrm{O}^{-1}$.

In the model of MEAD [15], the central compartment (Rc, Ic as above) is separated from the distal one ( $\mathrm{Rd}=$ $\left.3 \mathrm{cmH}_{2} \mathrm{O} \cdot l^{-1} \cdot \mathrm{s}, \mathrm{Cd} 50 \mathrm{ml} \cdot \mathrm{cmH}_{2} \mathrm{O}^{-1}\right)$ by the compliance of the central airways $\left(\mathrm{Cbr}=1 \mathrm{ml} \cdot \mathrm{cmH}_{2} \mathrm{O}^{-1}\right.$, i.e. one fifth of the value used by MEAD [15] for the adult lung). Zrs is given by:

$$
\mathrm{Zrs}=\mathrm{Zc}+\mathrm{Zd} \times \mathrm{Zbr} /(\mathrm{Zd}+\mathrm{Zbr})+\mathrm{Zw}
$$

Airway response to challenge is simulated by an increase in the resistance of the distal compartment to $10 \mathrm{cmH}_{2} \mathrm{O} \cdot l^{-1} \cdot \mathrm{s}$, i.e. $\mathrm{Rrs}=14 \mathrm{cmH}_{2} \mathrm{O} \cdot l^{-1} \cdot \mathrm{s}$.

To account for the effect of the upper airway wall in the models of OTIS [16] and MEAD [15], Zrs is finally replaced in equation (1) (standard generator) and equation (2) (head generator) by equation (4) in the first case, and equation (5) in the second case. Frequency dependence of resistance and compliance are then calculated from the data resulting from these simulations.

\section{References}

1. Peslin R, Fredberg JJ. Oscillation mechanics of the respiratory system. In: Fishman PA, Macklem PT, Mead J. eds. Handbook of Physiology. Section 3. The Respiratory System, Vol. 3. Mechanics of Breathing. Part 1. Baltimore, William \& Wilkins, 1986; pp. 145-177.
2. Stanescu D, Moavero NE, Veriter C, Brasseur L. Frequency dependence of respiratory resistance in healthy children. J Appl Physiol: Respirat Environ Exercise Physiol 1979; 47: 268-272.

3. Williams SP, Fullton JM, Tsai MJ, Pimmel RL, Collier AM. Respiratory impedance and derived parameters in young children by forced random noise. J Appl Physiol: Respirat Environ Exercise Physiol 1979; 47: 169-174.

4. Duiverman EJ, Clement J, Van de Woestijne KP, Neijens HJ, van den Bergh ACM, Kerrebijn KF. Forced oscillation technique. Reference values for resistance and reactance over a frequency spectrum of $2-26 \mathrm{~Hz}$ in healthy children aged 2.3-12.5 years. Bull Eur Physiopathol Respir 1985. 21: $171-178$.

5. Hantos Z, Daroczy B, Gyurkovits K. Total respiratory impedance in healthy children. Pediatr Pulmonol 1985; 1: 91-98.

6. Peslin R, Duvivier C. Gallina C, Cervantes P. Upper airway artifact in respiratory impedance measurements. Am Rev Respir Dis 1985; 132: 712-714.

7. Cauberghs M, Van de Woestijne KP. Effect of upper airways shunt and series properties on respiratory impedance measurements. J Appl Physiol 1989; 66: 2274-2279.

8. Marchal F, Haouzi P, Peslin R, Duvivier C, Gallina C. Mechanical properties of the upper airway wall in children and their influence on respiratory impedance measurements. Pediatr Pulmonol 1992; 13: 28-33.

9. Marchal F. Peslin R, Duvivier C, Gallina C, Crance JP. Mechanics of the ventilatory system in sedated infants: forced oscillations versus single-breath method. Pediatr Pulmonol 1988; 5: 9-26.

10. Marchal F, Peslin R, Duvivier C, Gallina C, Crance JP. Measurement of ventilatory mechanical impedance in infants using a head pressure generator. Pediatr Pulmonol 1989; 7: 209-216.

11. Peslin RC, Duvivier C, Didelon J, Gallina C. Respiratory impedance measured with head generator to minimize upper airway shunt. J Appl Physiol 1985; 59: 1790-1795.

12. Buhr WR, Jörres R, Berdel D, Làndsér FJ. Correspondence between forced oscillation and body plethysmography during bronchoprovocation with carbachol in children Pediatr Pulmonol 1990; 8: 280-288.

13. Peslin RF, Marchal F, Duvivier C, Ying Y, Gallina C. Evaluation of a modified head generator for respiratory impedance measurements. Eur Respir Rev 1991; 1: 140 145.

14. Van de Woestijne K. Recommendations and future plans. Eur Respir Rev 1991; 1: 236-237.

15. Mead J. Contribution of compliance of airways to frequency dependent behavior of lungs. J Appl Physiol 1969; 26: 670-673.

16. Otis $\mathrm{AB}, \mathrm{McKerrow} \mathrm{CB}$, Bartlett RA, et al. Mechanical factors in distribution of pulmonary distribution. $J$ Appl Physiol 1956; 8: 427-443. 